\title{
Repair Strategies for Hearing Impaired Adolescents based on Sentence Comprehension according to Language Ability
}

\author{
Ji-Ah Lee ${ }^{a}$, So-Young Choi ${ }^{\mathrm{b}}$ \\ ${ }^{a}$ Department of Special Education, Graduate School, Dankook University, Yongin, Korea \\ ${ }^{b}$ Graduate School of Special Education, Dankook University, Yongin, Korea
}

Correspondence: So-Young Choi, $\mathrm{PhD}$ Graduate School of Special Education, Dankook University, 152 Jukjeon-ro, Suji-gu, Yongin 16890, Korea

Tel: +82-31-8005-3813

Fax: +82-31-8021-7144

E-mail: syc529@dankook.ac.kr

Received: October 4, 2016

Revised: April 21, 2017

Accepted: May 10, 2017

This article is based on a part of the first author's master's thesis from Dankook University.

\begin{abstract}
Objectives: This study aimed to identify effective repair strategies for hearing impaired adolescents based on their language ability by studying differences in sentence comprehension. Various repair strategies were provided by a communication partner. Methods: Selected participants used a 20-45 dB range hearing aid, primarily used spoken language, and were age 14 to 18 . A high scoring group $(\mathrm{N}=18)$ and a low scoring group $(\mathrm{N}=18)$ were constructed according to language skills. This study investigated sentence comprehension using a sentence-picture matching task. When a communication breakdown occurred, a communication repair strategy — repetition, revision, or simplification — was provided by a communication partner. Results: The results showed that the rate of correct sentence comprehension in the high group was significantly higher than in the low group. When the communication partner used the communication repair strategy, the correct rate increased significantly in both groups. Although the efficacy of each strategy was no different from the others within the high group, the simplification strategy was more effective than repetition or revision in the low group. Conclusion: Repair strategies used by a communication partner have positive effects in improving communication breakdown. But there are differences in the usefulness of various repair strategies depending on the speaker's language skills.
\end{abstract}

Keywords: Hearing impaired adolescents, Communication repair strategy, Language ability
인공와우 수술이 보편화되고 조기에 청능재활과 언어치료를 병 행하는 청각장애 아동들이 증가하면서 말 지각과 어음변별, 표현 능력 등 언어발달이 향상됨에 따라 청각장애 아동들의 구어를 통 한 상호작용 기회가 확대되고 있다(Connor, Craig, Raudenbush, Heavner, \& Zwolan, 2006). 이와 함께 청각장애 학생들이 통합교육 을 선택하는 비율은 매년 증가하는 추세이지만 그 양상을 들여다 보면 초등부 과정에서 일반학교를 선택하는 학생의 수가 가장 많았 고 중고등부 과정으로 올라갈수록 통합교육을 선택하는 학생의 수가 크게 감소하는 양상으로, 통합환경을 선호하여 선택하였지만 통합환경에 적응하지 못하고 다시 청각장애 학교로 복귀하는 현상 을 보이고 있다(Damen, van den Oever-Goltstein, Langereis, Chute, \& Mylanus, 2006; Oh, 2012). 청각장애 학생들이 통합환경에 부적
응하는 대표적 이유는 의사소통의 어려움으로 알려져 있으며, 인 공와우 이식 아동들의 통합학급에서의 수행을 살펴 본 Coates와 Sutton-Spence (2001)는 이 아동들이 상대방의 말을 완전하게 듣 지 못하고 부분적으로 듣거나 혹은 듣더라도 의미를 이해하지 못 해서 대화가 중단되는 경우가 많다고 보고하였다. 자신의 생각이나 감정을 적절한 시기에 효과적으로 표현할 수 있는 의사소통 기술 은 청각장애 학생들이 통합 환경에서 복잡하고 다양한 주제의 대 화에 참여하고 교사 및 친구들과 바람직한 사회적 관계를 형성하 기 위해 매우 중요하다(Lin, Lawrence, \& Gorrell, 2003; Oh, 2012). 그러나 청각장애인은 청력의 손실로 인해 언어의 표현 및 수용능력 에 결함을 갖게 되며, 구문규칙이나 문장이해에 어려움이 있고, 연 속적인 구어 산출 시 적절하지 못한 발성 등으로 정확한 의미전달 
이 제한되는 등 듣기와 말하기를 비롯한 여러 언어영역에서 문제를 보인다(Huh, 1997; Jeong, 2001; Lee \& Lee, 1993). 이러한 문제들로 인해 청각장애인은 의사소통 상대자의 의도된 구어 메시지를 이해 하는데 실패하게 되며, 건청인과의 의사소통은 물론 청각장애인 간에도 의사소통 붕괴(communication breakdown)가 자주 일어나 게 된다.

이러한 의사소통 붕괴 상황에서 나타나는 의사소통 회복전략 (communication repair strategy)은 신호를 수정하거나 변경하여 대화를 유지시키기 위한 노력으로, 화자의 구어가 불분명하거나주 어진 발화를 잘못 이해하였을 때 의사소통을 지속하기 위하여 사 용되곤 한다(Wetherby \& Prizant, 2002). 이러한 전략에는 반복하 기(repetition), 바꾸어 말하기(revision), 간략히 말하기(reduction/ simplification), 단서추가(cue) 등이 포함된다(Gallagher, 1977; Jeanes, Nienhuy, \& Rickards, 2000; Lee \& Seok, 2003). 청각장애인이 당면 하는 의사소통의 어려움과 단절된 의사소통을 회복하기 위한 전 략 사용은 여러 연구에서 다루어져 왔다(Berger, 1973; De Filippo \& Scott, 1978; Gagne \& Wylliet, 1989; Owens \& Telleen, 1981; TyeMurray, Purdy, Woodsworth, \& Tyler, 1990). 본 연구에서는 의사 소통 회복전략과 관련한 선행연구들에서 청각장애 참가자들에게 사용 빈도가 높은 것으로 관찰된 바 있고(McTear \& Conti-Ramsden, 1992) 회복전략을 적용했을 때 각 문장의 특성이 두드러지게 달라지도록 하기 위하여 반복하기, 바꾸어 말하기, 간략히 말하기 를 사용하였다.

일부 보고된 국내 연구에 따르면, 인공와우를 착용한 아동들은 건청 아동에 비해 대화가 단절되는 비율이 높고 청자의 요구에 부 적절한 반응을 보이는 비율이 높게 보고되었으나 명료화 요구 및 발화수정전략을 사용하는 빈도는 두드러진 차이를 보이지 않았다 (Kim, 2011; Lee, 2006). 반면 7세, 9세, 11세 청각장애 아동과 건청 아동의 발화수정전략 유형별 사용률을 살펴본 Choi (2001)의 연구 에서는 두 집단이 사용하는 발화수정전략의 양상이 다르게 관찰 되었다. 청각장애 집단의 경우 반복과 부적절한 반응을 보이는 비 율이 건청 아동에 비해 높았던 데 비해, 대치(이전 발화의 낱말을 같은 의미의 다른 낱말로 바꾸어 표현), 도치(이전 발화의 문장순서 를 바꾸어 표현), 첨가(이전 발화에 새로운 낱말, 구, 문장을 첨가하 여 표현) 등 선행 발화의 내용을 다양한 형태로 바꾸어 표현하는 보다 세밀한 전략의 사용률은 낮았다. 그러나 의사소통 회복전략 과 관련하여 진행된 국내연구는 여전히 부족한 실정이고, 특히 대 부분이 학령전기 청각장애 아동과 건청 아동의 의사소통 특성을 비교하는 연구이거나 청각장애를 동반한 성인을 대상으로 한 연구 가 많은데 반해 청소년을 대상으로 한 연구는 부족한 실정이다(Heo
\& Ha, 2010; Lee, Sung, Park, \& Sim, 2011). 의사소통의 어려움은 고학년이 되고 상급학교에 진학하는 시기에 더 많이 경험할 수 있 고 또래관계가 확장되고 독립성이 강해지는 시기인 청소년 시기와 도 맞물려 있다. 청소년기는 구조화된 환경에서의 상호작용보다 개 방된 환경에서 다양하고 새롭고 낮선 의사소통 상대자와 만나는 기회가 확대되는 시기로 대인관계를 통한 상호작용의 중요성이 증 가하는 시기이다(Kang, 2011). 동시에 또래 반응에 매우 민감한 시 기로 이때 경험하는 부정적인 반응과 의사소통 실패 경험은 낮은 자기효능감(self-efficacy)을 형성하게 할 수 있다(Smith \& West, 2006). 따라서 청각장애 청소년이 겪고 있는 의사소통의 어려움을 확인하고 적극적인 개입을 위한 체계적인 연구가 요구된다.

한편, 의사소통의 효율성과 의사소통 단절 시 회복전략을 얼마 나 성공적으로 사용할 수 있는가는 대화상황 및 의사소통 파트너, 또는 언어정보를 활용하는 개인의 능력에 따라서 차이가 있을 수 있다(Tye-Murray, 2009). 먼저, 의사소통 과정이란 화자와 청자가 각자의 역할을 잘 이해하고 수행하는 상호작용을 기반으로 하기 때문에 청각장애를 가진 이들과 상호작용하는 의사소통 상대자의 역할도 매우 중요하다고 할 수 있다. 즉, 청각장애를 지닌 화자 스스 로 의사소통 회복전략을 활발히 사용하는가에 대한 연구도 의의 가 있지만 의사소통 상대방이 제시하는 회복전략을 적절히 수용 하여 대화의 단절을 극복할 수 있는가와 더불어 어떠한 회복전략 이 청각장애인에게 보다 효과적인지를 탐색하는 연구가 필요하다. 앞서 살펴본 바와 같이 기존에 보고된 연구들은 주로 청각장애를 가진 아동들이 비구조화된 의사소통 상황에서 사용하는 회복전 략의 빈도를 조사하여 보고하였는데, 이 같은 시도는 청각장애 아 동이 비교적 자연스러운 상황에서 화자로서 의사소통 회복전략을 사용하는 측면을 파악하고자 하였으나 대화 단절이 발생하는 시점 과 전략을 사용하는 양상에 개인차가 있고 대화 상대가 제공하는 발화수정전략의 효과를 설명하기에는 제한적이었다. 이에 본 연구 는 문장-그림 일치 과제(sentence-picture matching task)를 활용하 여 구조화된 환경을 설정하고 연구자가 제시하는 문장과 일치하는 그림을 고르도록 하였을 시 오반응이 발생한 상황을 주어진 자극 에 대한 이해 실패 또는 불충분한 이해로 간주하였다. 이때, 의사소 통 회복전략을 추가로 제공함으로써 의사소통 상대자가 사용하는 회복전략이 청각장애를 지닌 대상자들의 반응 정확도에 영향을 미 치는지, 회복전략 유형에 따라 반응 정확도에 차이가 있는지 알아 보았다.

다른 한편으로는, 어휘력을 비롯한 개인의 언어능력이 의사소통 회복전략의 사용 빈도나 효율성에 영향을 미칠 가능성도 염두에 두어야 한다. 앞서 언급하였듯이 청각장애를 조기에 발견하여 일찌 
감치 인공와우나 보청기 등 보장구를 착용하고 청능 및 언어재활 을 시작하는 것은 청력손실로 인한 영향을 보완하여 청각장애 아 동들의 말 지각 능력 개선과 구어발달에 도움을 줄 수 있다(Pisoni \& Cleary, 2003; Svirsky \& Chin, 2000). 그러나 이 같은 조기 중재에 도 불구하고 청각장애 아동들의 듣기 능력은 제한적일 수 있으며 여전히 일반아동들에 비해 문법이나 의미 측면의 언어영역에서 낮 은 수행을 보인다고 알려져 있다(Johnson \& Goswami, 2010). 언어 능력을 구성하는 여러 요인 중 단어를 이해하거나 구사하는 언어 사용자의 어휘지식은 학습을 위해 기본적으로 갖추어야 할 능력 으로, 쓰기는 물론 문장이해나 독해력과 밀접한 관련이 있음이 여 러 연구들을 통해 밝혀졌다(Kim, 1993; Kim \& Hwang, 2008; Ok \& Yoon, 2008). 청각장애 아동의 어휘는 독특한 분류체계를 가지 며, 이들은 추상적인 단어보다 친숙한 행위와 관련된 명사와 동사 를 더 쉽게 이해하는 경향이 있다(McAnally, Rose, \& Quigley, 1999). 또한 청각장애 학생은 건청 학생에 비해 사용어휘가 매우 제한적일 뿐 아니라(Kim, 2007; Lee, 1993; Paul \& Gustafson, 1991) 문맥과 상관없는 어휘를 사용하는 경우가 많으며, 많은 단어를 포함하는 길이가 긴 문장이나 구문구조가 복잡하고 의미가 어려운 문장을 처리할 때 오류를 많이 보인다(Park \& Bahng, 2011). 이러한 문제의 원인은 청력의 제한으로 단어의 세밀한 부분을 듣지 못하는 데 있 을 수 있으나, 어휘지식이 양적으로 부족하거나 단어의 다양한 의 미에 대한 구체적인 경험이 부족하여 문장 내의 단어가 내포하고 있는 맥락적인 의미를 이해하기보다 단어의 표면적인 뜻에 치중하 는 등 어휘의 다양한 활용에 제한이 있기 때문일 수 있다. 그에 따 라 본 연구는 선행연구들에서 청각장애 아동의 이 같은 특성이 충 분히 고려되지 못한 점을 고려하여 어휘력을 바탕으로 언어 수준 이 다른 두 집단을 구성한 뒤 의사소통 상대방에 의해 제시되는 회 복전략을 활용하는 양상에 차이가 있는지 확인해보고자 하였다.

정리하자면, 본 연구는 청각장애 집단과 건청 집단을 비교하는 연구에서 나아가 중·고등학교에 재학 중인 청각장애 청소년을 대 상으로 하였으며, 이들의 어휘력을 바탕으로 언어 수준이 다른 두 집단을 구성하여 문장이해 수행에 차이가 있는지를 살펴보고자 하였다. 더불어 청각장애 청소년이 청자 입장일 때 화자인 대화 상 대자의 역할을 확인하고자 의사소통 상대자에 의해 제시되는 회복 전략 유형에 따라 언어 수준이 다른 두 집단 간 문장이해 수행에 차 이가 있는지 체계적으로 측정하였다. 구체적인 연구문제는 (1) 청각 장애 청소년의 언어능력에 따라 문장이해 정확도에 차이가 있는 지 와, (2) 언어능력이 다른 두 집단 간에 의사소통 상대자가 제시하는 회복전략 유형에 따른 수정반응 정확도에 차이가 있는지 알아보는 것이다. 연구 결과를 통해 청각장애를 가진 청소년 본인은 물론 또
래집단과 교사, 가족 등 주 의사소통 상대자에게 의사소통 단절을 효율적으로 회복할 수 있는 전략을 제안할 수 있을 것으로 보았다.

\section{연구방법}

\section{연구대상}

본 연구는 서울 및 경기 지역에 소재하는 청각장애 특수학교에 재학 중이거나 일반학교에서 통합교육을 받는 생활연령 14-18세인 중·고등학생을 대상으로 하였다. 이들은 (1) 부모 및 교사 보고에 따라 청각장애 외에 다른 신체, 정서, 사회성 및 인지능력에서 특이 한 문제를 보이지 않고, (2) 한국판 아동용 웩슬러 지능검사(Korean Wechsler Intelligence Scale for Children, K-WISC-III) 결과 동 작성 지능이 80 이상이며, (3) 구어를 단일 언어나 제 1 언어로 사용 하는 청각장애 청소년으로, (4) 말소리 주파수가 집중되어 있는 500 $\mathrm{Hz}, 1,000 \mathrm{~Hz}, 2,000 \mathrm{~Hz}$ 평균을 나타내는 3 분법으로 측정한 보정 청력이 경도난청 범위인 20-45 dB에 속하였고, (5) 최소한 학령기 수준의 어휘수준을 가진 학생을 대상자를 모집하기 위한 연구목 적에 따라 수용·표현 어휘력검사(Receptive \& Expressive Vocabulary Test, REVT; Kim, Hong, Kim, Jang, \& Lee, 2009)에서 등가연 령이 8-14세 범위에 해당되었다. 연구에 참여한 대상자는 총 36명이 었으며 수용언어(REVT-R) 등가연령을 기준으로 11-14세에 해당 하는 학생은 상위집단, 8-10세에 해당하는 학생은 하위집단으로 구성하였다. 이때 집단을 나누는 기준은 청각장애 특수학교에 재 학 중인 중학교 1 학년부터 고등학교 2학년까지 청소년을 대상으로 수용·표현 어휘력검사를 실시한 결과 언어연령 평균이 10 세 6개월 수준(범위 4;10-15;11)이라는 선행연구 결과를 참고로 하였다(Kang \& Ha, 2013). 어휘력에 따른 언어 수준으로 구분된 상위집단과 하 위집단 간 동질성을 확인하기 위해 독립표본 $t$-검정(two-independent sample $t$-test)을 실시한 결과, 생활연령, 청력 및 동작성 지능 점수에서는 집단 간에 통계적으로 유의미한 차이가 없었고, 언어연 령에서만 상위집단이 하위집단보다 유의미하게 높은 것으로 나타 났다 $\left(t_{(28.809)}=11.216, p<.05\right)$. 집단별 참가자 정보는 Table 1과 같고,

Table 1. Participants' characteristics

\begin{tabular}{lccc}
\hline & $\begin{array}{c}\text { Gender } \\
\text { (male:female) }\end{array}$ & $\begin{array}{c}\text { CA } \\
(\mathrm{mo})\end{array}$ & $\begin{array}{c}\text { Age-equivalent } \\
\text { score }^{\mathrm{a}}\end{array}$ \\
\hline High group $(\mathrm{N}=18)$ & $8: 10$ & $15.72(1.12)$ & $12.77(1.30)$ \\
Low group ( $\mathrm{N}=18)$ & $12: 6$ & $16.33(.76)$ & $8.66(.84)$ \\
\hline
\end{tabular}

Values are presented as mean (SD).

$\mathrm{CA}=$ chronological age

${ }^{\text {aREVT-R }}=$ Receptive \& Expressive Vocabulary Test-receptive vocabulary (Kim, Hong, Kim, Jang, \& Lee, 2009). 
청력 수준의 상세는 Appendix 1에 제시하였다. 참가자들의 일반적 인 특성은 보장구 착용은 인공와우(cochlear implantation, $\mathrm{CI}$ ) 착 용자가 $61.1 \%$ 으로 가장 많았고, 보청기(hearing aid, HA) 착용자가 $27.8 \%$, 보청기와 인공와우를 함께 착용한 참가자가 $11.1 \%$ 였다. 보정 청력범위는 $20-30 \mathrm{~dB}$ 가 $41.7 \%, 30-40 \mathrm{~dB}$ 가 $41.7 \%, 40-50 \mathrm{~dB}$ 가 $16.6 \%$ 로 평균 30-40 dB였다. 교육형태는 특수학교에 재학 중인 학생이 $72.2 \%$, 일반학교에서 통합교육을 받는 학생이 $27.8 \%$ 였다.

\section{연구도구}

본 연구에서는 청각장애 청소년을 대상으로 문장-그림 일치(sentence-picture matching) 과제를 실시하였다. 이 과제는 시각적으로 제시된 그림 자극 중 들려준 문장과 일치하는 하나의 그림을 선택 하는 것으로, 주어진 문장을 정확하게 이해하고 판단하여 반응하 는 수행이 필요하다. 연구자가 1차 제시한 문장을 대상자가 이해하 지 못하고 정확한 반응에 실패한 경우를 의사소통 단절이 발생한 상황으로 간주하고 의사소통 회복전략을 제시하는 방식을 도입하 여 의사소통 회복전략 사용에 따른 문장이해 정확도 차이와 회복 전략의 유형 간에 수행 차이가 나타나는지 관찰하였다.

과제는 총 30 개의 문장으로 구성되었으며, 사동 및 피동 형태소, 조사, 부정, 연결어미 등 문법형태소에 초점을 둔 문장과 문법적 요 소에 부합한 안긴문장(관형절, 명사절, 부사절)과 이어진 문장(대 등절, 조건절, 종속절) 같은 다양한 문장형식이 포함되도록 선행연 구의 자극을 참고하여 수정·보완하였다(Hwang, 2013; as cited in Lee \& Seok, 2003). 한 문항에 4 개의 그림 보기가 주어지는데, 그 중 한 장만이 연구자가 제시한 문장과 일치하는 그림이고 나머지 세 장의 그림은 성별, 행위자, 대상, 동작, 배경 등에 변화를 주어 오답 으로 구성하였다. 문장-그림 일치 과제의 예시는 Appendix 2에 제 시하였다. 회복전략 유형별로 10 개씩의 자극 문장이 할당되었으며 검사 자극은 동일한 회복전략이 세 번 이상 연속되거나 같은 유형 의 문장이 두 번 이상 연달아 제시되지 않도록 유사무선배열(quasi random order)하였고 문장과 일치하는 정답 그림의 위치는 1 번부 터 4 번까지 동일한 비율이 되도록 조정하여 제시하였다.

본 연구에서 의사소통 회복전략 사용에 따른 문장이해 차이를 알아보기 위해 대상자에게 주어진 전략 유형은 반복, 바꾸어 말하 기, 간략화 전략이었다. 반복은 검사문장을 그대로 다시 반복하여 들려주는 것이고, 바꾸어 말하기는 다른 어휘를 사용하거나 구문 구조를 변형하여 검사문장과 유사한 의미를 갖도록 재구조화한 뒤 들려주는 것이며, 간략화는 어휘의 수나 난이도를 조정하여 검 사문장의 복잡성을 감소시켜 들려주는 것이다(Marzolf, Stewart, Nerbonne, \& Lehman, 1998). 의사소통 회복전략의 유형별 차이를
분명하게 할 수 있도록 바꾸어 말하기 상황에서는 문장구조와 배 열에 변화를 주되 본래 문장과 음절수를 같게 하여 자극 길이는 동 일하게 유지하였고, 간략화 상황에서는 총 어휘수나 음절수를 줄 여서 자극 길이에 변화가 있도록 하였다. 본 실험에 앞서 검사도구 의 타당성과 난이도의 적절성 및 실험절차를 검증하고자 두 차례 의 예비실험을 시행하였고 그 결과를 바탕으로 청각장애 청소년의 문장이해 측정에 제한이 있다고 판단되는 문장의 어휘와 구문을 수정하였다. 언어병리학전공 교수와의 논의를 통해 수정한 검사도 구의 어휘, 구문, 내용 타당도를 최종 검토한 후 과제문장을 완성하 였다. 전체 검사문장 및 의사소통 회복전략을 적용한 문장의 목록 은 Appendix 3에 제시하였다.

\section{연구절차}

검사는 조용하고 독립된 공간에서 연구자와 대상자 일대일로 실 시하였다. 본 연구는 연구자가 청각장애 청소년의 의사소통 파트너 가 되어 문장을 제시하고 대상자가 이해에 실패한 상황에서 의사 소통 회복전략을 추가로 제공하는 역할을 하는 구조화된 상황의 상호작용적 의사소통을 적용하였다. 회복전략을 제시하게 되는 상 황은 (1) 1 차 문장 제시가 끝난 뒤 5 초 내에 그림을 선택하지 못했거 나, (2) 문장과 일치하는 적절한 그림을 선택하지 못하고 오반응 한 경우, (3) 대상자가 명료화 요구를 하는 경우로 명료화 요구에 대해 서는 비특정적 명료화 요구(nonspecific request)와 특정적 명료화 요구(specific request)를 모두 허용하였다(Jeanes et al., 2000).

모든 문장은 연구자가 사전연습과 예비실험을 통해 표정, 속도, 억양 등 기타변수를 최소화하여 직접 제시하였고, 구어를 사용하 는 청각장애 청소년들이 일반적으로 경험하는 대화상황에 가까운 조건으로 구조화하고자 청각과 시각적 단서를 모두 사용하는 $\mathrm{AV}$ (auditory/visual) 조건에서 한 번씩만 들려주었다. 참가자들은 연 습 시행을 통해 과제 시행 절차 및 취할 수 있는 명료화 요구에 대해 설명을 들었고, 대상자의 청각장애 특성을 고려하여 경우에 따라 검사 지시사항을 전달할 때는 수화를 보조적으로 사용하였다. 참 가자가 충분히 숙지한 것으로 판단되면 본 시행을 실시하였다.

\section{자료분석}

두 집단의 언어 수준과 의사소통상대자에 의해 제시된 회복전략 에 따라 문장이해 수행에 차이가 있는지 비교하고자 전체 제시된 자 극 중 적절하게 응답한 비율을 계산하여 반응 정확도를 분석하였다. 회복전략 제시 없이 대상자의 언어 수준에 따라 문장이해 수행에 차이가 있는지 알아보기 위해 문장이해 정확도를 계산하였고, 의사 소통 붕괴로 간주된 상황에서 회복전략을 제시한 후의 집단 간 문 
장이해 수행 차이를 확인하기 위해 수정반응 정확도를 계산하였다.

수집된 자료는 SPSS Window 18.0으로 처리하였다. 집단 간의 반 응 정확도에 유의한 차이가 있는지를 알아보기 위해 문장이해 정 확도와 수정반응 정확도 각각에 대한 독립표본 $t$-검정을 실시하였 고, 제시된 회복전략 하위유형별 집단 간 차이가 통계적으로 유의 한지 알아보고자 집단(2)과 전략유형(3)을 요인으로 하는 반복측 정 분산분석(repeated measure two-way ANOVA)을 실시하였다.

\section{연구결과}

\section{문장이해 정확도}

총 30 문항 중 언어 수준 상위집단의 정반응 개수가 평균 13 문항 (43.94\%)으로 하위집단의 평균 6문항(21.33\%)보다 유의미하게 높 았다 $\left(t_{(34)}=6.749, p<.05\right)$. 이는 상대적으로 높은 어휘력을 지닌 청 각장애 청소년의 문장이해 정확도가 높음을 보여주었다. 두 집단 의 1 차 수행에 대한 정반응 개수 및 문장이해 정확도의 평균과 표 준편차는 Table 2와 같다.

한편, 대상자의 부적절한 1 차 반응에 대하여 회복전략이 제시된 상황을 추가적으로 살펴본 결과 집단 간 양상에 다소 차이가 관찰 되었다. 언어 수준 상위집단은 시간초과로 인해 전략이 제시된 경우 가 가장 많았고 이어서 오반응과 명료화 요구 순으로 나타난 것과 달리, 하위집단은 오반응으로 인한 전략제시가 가장 많았고 이어서 시간초과와 명료화 요구 순으로 나타났다. 세 가지 상황 중 상위집단 과 하위집단 간의 차이가 유의미했던 것은 시간초과와 $\left(t_{344}=2.447\right.$, $p<.05)$ 오반응에서 $\left(t_{(34)}=-3.862, p<.05\right)$ 이었고, 대상자의 명료화 요구로 인한 회복전략 제시 빈도에서는 두 집단 간에 통계적으로 유의미한 차이는 없었다 $\left(t_{(26.077)}=1.715, p>.05\right)$.

Table 2. Number of correct response and correct percentage of response according to the groups

\begin{tabular}{lcl}
\hline & Number of correct responses & \multicolumn{1}{c}{$\%$} \\
\hline High group & $13.16(3.20)$ & $43.94(10.67)$ \\
Low group & $6.33(2.72)$ & $21.33(9.38)$ \\
\hline
\end{tabular}

Values are presented as mean (SD).

Table 3. Number of correct response and correct percentage of response according to the groups (after a repair strategy had been proposed)

\begin{tabular}{lccc}
\hline & $\begin{array}{c}\text { Number of repair } \\
\text { strategies proposed }\end{array}$ & $\begin{array}{c}\text { Number of correct } \\
\text { responses }\end{array}$ & $\%$ \\
\hline High group & $16.88(3.20)$ & $16.05(2.50)$ & $95.83(5.33)$ \\
Low group & $23.66(2.72)$ & $19.38(2.61)$ & $82.11(9.58)$ \\
\hline
\end{tabular}

Values are presented as mean (SD).

\section{수정반응 정확도}

Table 3에 제시된 바와 같이, 의사소통 상대자가 회복전략을 제 시한 이후의 문장이해 과제 수행을 나타내는 수정반응 정확도 역 시 언어 수준 상위집단이 평균 $95.83 \%$ 로 하위집단 평균 $82.11 \%$ 에 비해 유의미하게 높았다 $\left(t_{(26.622)}=5.306, p<.05\right)$. 또한 Table 2 와 비 교하여 회복전략을 제시하기 전과 후의 집단별 반응 정확도를 살 펴보면 언어 수준 상위집단의 경우 약 $44 \%$ 에서 약 $96 \%$ 로, 하위집 단 또한 약 $21 \%$ 에서 약 $82 \%$ 로 높아진 결과를 보여 의사소통 회복 전략이 청각장애 청소년의 문장이해 수행 시 적절한 반응을 유도 하는데 도움이 되었음을 확인할 수 있었다.

대상자의 부적절한 1 차 반응에 대하여 주어진 회복전략의 총 제 시율은 언어 수준 하위집단이 30 문항 중 평균 24 문항(78.77\%)으 로 상위집단이 평균 17 문항(56.00\%)인 것에 비해 유의하게 높아 하 위집단에서 의사소통 회복전략이 더 많이 요구되었음을 반증하였 다 $\left(t_{(34)}=-6.899, p<.05\right)$. 그러나 각 집단 내에서 주어진 전체 회복전 략 중 각 유형이 차지하는 비율은 두 집단 간에 유의한 차이를 보이 지 않았다 $\left(t_{(21.151)}=.086 ; t_{(27.504)}=-.669 ; t_{(24.566)}=.587, p s>.05\right)$. 즉, 두 집단에서 세 가지 전략 유형은 유사한 비율로 제시되었기에 주어진 회복전략 유형에 따른 문장이해차이를 분석할 수 있었다.

의사소통 상대자가 제시한 회복전략 유형에 따라 청각장애 청소 년의 문장이해에 차이가 있는지, 그리고 참가자들의 어휘력에 근거 한 언어 수준에 따른 차이와의 상호작용이 있는지 집단(2)과 전략 유형(3)을 요인으로 하는 반복측정 분산분석(repeated two-way ANOVA)을 실시하여 분석한 결과 집단에 따른 주효과가 나타났으 나 $\left(F_{(1,34)}=25.737, p<.05\right)$ 청각장애 청소년에게 제시된 회복전략 유 형에 따른 주효과는 통계적으로 유의미하지 않았다 $\left(F_{(2,68)}=1.486\right.$, $p>.05)$. 단, 집단과 회복전략 유형의 상호작용 효과는 유의미한 것 으로 나타났다 $\left(F_{(2,68)}=8.448, p<.05\right)$. 즉, 수정반응 정확도에 대한

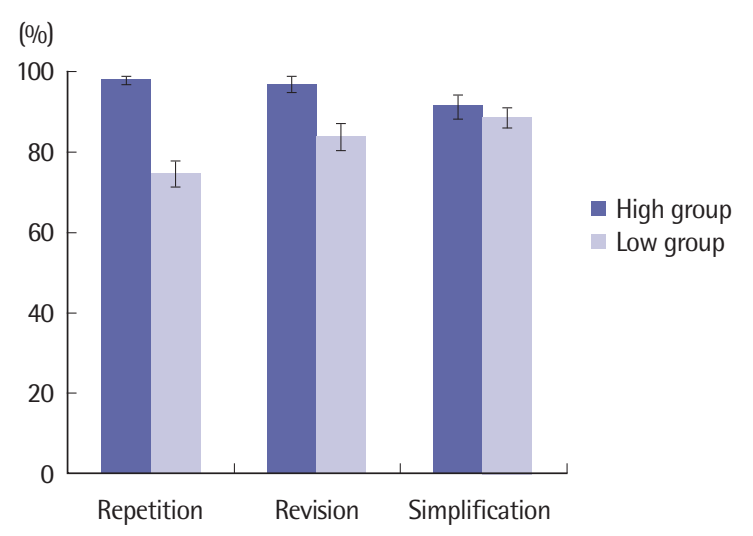

Figure 1. Correct percentage of response according to the groups and conditions. 
집단의 주효과가 관찰됨에 따라 상대적으로 높은 언어 수준을 가 진 청각장애 청소년이 회복전략 제시 후에도 더 높은 반응 정확도 를 나타내는 것으로 확인되었으나 회복전략 유형에 따른 주효과는 나타나지 않았는데 이는 언어 수준 상위집단의 경우 전략별 수행 차이가 미미하였기 때문으로 추정된다. 집단과 회복전략 유형에서 나타난 상호작용 효과 역시 의사소통 상대자가 제시하는 회복전략 의 하위 유형 별 문장이해 수행 양상이 언어 수준의 높고 낮음에 따라 차이가 있음을 시사하였다. Figure 1을 통해 상호작용 양상을 좀 더 자세히 살펴보면 가장 높은 반응 정확도가 관찰된 회복전략 에서 차이가 있었는데, 언어 수준 상위집단은 반복 전략이 제시되 었을 때 수정반응 정확도가 가장 높았고(평균 $98.11 \%$ ), 하위집단의 경우는 간략화 전략을 적용했을 때 수정반응 정확도가 가장 높게 나타났다(평균 88.77\%). 그러나 사후 검정(post-hoc test) 결과, 집단 간 수행 차이는 반복 전략 $\left(F_{(1,34)}=44.416, p<.01\right)$ 과 바꾸어 말하기 전략 $\left(F_{(1,34)}=11.981, p<.01\right)$ 에서만 통계적으로 유의하였고, 간략화 전략에서는 집단 간의 차이를 보이지 않았다 $\left(F_{(1,34)}=.467, p>.05\right)$.

\section{논의 및 결론}

본 연구는 청각장애 청소년을 대상으로 이들의 언어 수준에 따 라 문장이해에 차이가 있는지 알아보고자 청각장애 청소년 36명을 어휘력에 근거한 언어 수준에 따라 상위집단과 하위집단으로 구분 하여 과제 수행 결과를 비교해보았다. 또한 이해 실패가 발생한 상 황에서 의사소통 상대자에 의해 반복, 바꾸어 말하기, 간략화 세 유 형의 회복전략이 주어졌을 때 전략 유형에 따른 수정반응 정확도에 차이가 나타나는지 살펴보았다. 주요 연구 결과는 다음과 같다.

첫째, 언어 수준 상위집단의 문장이해 정확도가 하위집단에 비 해 높은 것으로 나타나 언어 수준에 따라 자극을 듣고 이해하여 적 절히 반응하는데 차이가 있음을 알 수 있었다. 한편, 1 차 자극 제시 에서 발생한 이해 실패를 토대로 회복전략을 제시하게 되는 상황 에서도 두 집단은 다소 차이를 보였는데, 상위집단은 제한된 시간 내에 응답하지 못하여 전략을 제시하는 경우가 가장 많았고, 하위 집단은 오반응으로 인한 비율이 높았다. 두 집단 모두 연구 진행 방 식을 충분히 이해하고 수행하였음을 전제로 이러한 양상의 원인을 추정해 보았을 때, 상위집단은 제시된 문장을 듣고 이해하는 데 있 어 처리 속도나 효율성이 낮은 경우 오류가 발생하지만 하위집단은 처리 자체가 실패하는 오류에서 어려움이 비롯된 것으로 해석할 수 있었다. 그러나 본 연구에서 직접적으로 반응시간을 측정하거나 실시간 처리 과정을 관찰하여 분석한 것은 아니기 때문에 보다 정 확한 파악을 위해서는 추가적인 탐색이 요구된다. 둘째, 의사소통
회복전략을 제시하기 전과 후의 문장이해 수행을 비교한 결과 두 집단 모두 반응 정확도가 높아진 것으로 관찰됨에 따라 의사소통 상대자에 의해 제공되는 의사소통 회복전략이 청각장애 청소년의 문장이해 정확도에 긍정적인 영향을 준다는 점이 확인되었다. 셋 째, 두 집단의 언어 수준 및 제시된 의사소통 회복전략의 유형에 따 른 문장이해 수행을 분석한 결과에서는 각 집단에서 상대적으로 높은 반응 정확도를 보인 회복전략 유형이 서로 다른 경향을 보였 다. 상위집단의 경우 세 전략 유형 간에 큰 차이가 없이 고르게 높 은 반응 정확도를 보인 것에 비해, 하위집단의 경우는 단순히 선행 자극을 동일하게 다시 들려주는 반복 전략이나 동일한 문장이되 어순이나 구문 형태를 변형하여 표현하는 바꾸어 말하기 전략이 주어졌을 때보다 핵심을 간추려서 말하는 간략화 전략이 주어졌 을 때에 높은 반응 정확도를 보였다. 특히 간략화 전략이 제시된 조 건에서 상위집단과 통계적으로 유의한 차이가 나지 않는 수준의 수 행을 보인 결과는 상대적으로 낮은 언어 수준을 지닌 대상자에게 간략화 전략이 보다 유용한 기술임을 시사하였다. 다만, 회복전략 유형에 따른 주효과 자체는 통계적으로 유의미한 수준에 도달하지 못하여 해석에 주의를 요한다. 이는 상위집단의 경우 모든 전략에 서 $90 \%$ 이상의 높은 반응 정확도를 나타내어 전략 간 효용성의 차 이가 두드러지지 않았기 때문으로 추정되며, 전체 대상자 수 및 회 복전략 유형별 시행 수가 다소 적고 과제 문장의 난이도가 비교적 어렵지 않았던 점이 영향을 주었을 수 있다.

본 연구의 결과는 의사소통 파트너가 사용하는 회복전략에 따 른 성공적인 메시지 전달을 보여주고자 한 Tye-Murray와 Kelsey (1993) 연구와 유사한 양상을 보였는데, 그에 따르면 동일한 지시를 반복하는 전략은 메시지 전달에 큰 효과가 없었고 지시를 고쳐 말 하거나 핵심적인 단어를 강조하여 간략하게 나누어 메시지를 전달 했을 때 효율적인 메시지 전달이 가능한 것으로 나타난 바 있다. 그 러나 일부 선행연구들은 다른 결과를 보고하였는데, Tye-Murray 등(1990)의 연구에서는 문장 수준에서 시각적 확인(visual identification)을 용이하게 하는 5 가지 회복전략에 대해 실험한 결과 5 가 지 유형들 간에 통계적으로 유의미한 차이가 없는 것으로 나타났 고, 고도난청 아동들을 대상으로 의사소통 회복전략의 효과를 살 펴본 Lee와 Seok (2003)의 연구에서도 핵심단어전략을 제외한 나 머지 전략에서는 두드러진 차이가 관찰되지 않았다. 연구 결과들 에서 보여지는 이 같은 차이는 연구에 참여한 대상자들의 속성과 관련이 있을 수 있다. 본 연구의 경우 유사하게 진행된 선행연구들 이 주로 구어 사용이 제한적인 고도난청 아동을 대상으로 한 것과 달리 청력과 구어수준을 선별조건에 포함하여 일정수준 이상의 청 력을 유지하고 구어를 사용한 의사소통 요구가 있는 청각장애 청 
소년을 대상으로 하였다. 때문에 의사소통 상대자가 사용하는 회 복전략 유형에 따라 문장이해 정확도에 차이가 있을 수 있고, 특히 낮은 언어 수준을 지닌 대상자에게는 간략화 전략을 사용하는 것 이 가장 효과적일 수 있다는 본 연구의 결과는 이러한 집단에 대하 여 제한적인 해석과 적용이 가능할 것이다. 그러나 선행연구들과 본 연구가 공통적으로 강조하고자 하는 바는, 아무리 청각장애인 과 빈번하게 의사소통 하는 주 상대자라 할지라도 의사소통 회복 전략에 대한 지식과 기술은 자연적으로 획득할 수 있는 것이 아니 기 때문에 보다 효과적인 의사소통을 위해서는 청각장애를 지닌 대상자 본인뿐 아니라 의사소통 상대자에게도 직접적인 의사소통 전략 훈련이 필요하다는 점이다(Tye-Murray \& Kelsey, 1993; TyeMurray, 2009). 다만, 청각장애인의 연령이 증가할수록 그들이 대 면하는 의사소통 상대자는 불특정 다수가 되는 점을 고려할 때 의 사소통 환경이 제한적인 연령대의 경우 또래와 가족 중심의 의사 소통 회복전략 훈련을 실시하도록 하고, 의사소통 관계에서 주체적 인 역할이 가능해지는 보다 높은 연령대의 경우 청각장애 학생 본 인에게 유용한 의사소통 전략을 우선적으로 파악하도록 교육하여 대화 시 상대방에게 능동적으로 전략 사용을 요구할 수 있도록 훈 련하는 것도 실질적인 방안이 되리라고 본다.

본 연구가 지니는 몇 가지 제한점은 다음과 같다. 첫째, 연구 절차 상 제시된 회복전략의 하위유형별 시행 수가 충분하지 않고 그림으 로 구현해야 하는 연구 기법상 사용 가능한 문장의 형태와 난이도 가 제한되었기 때문에 결과를 일반화하여 적용하는 데 제약이 있 을 수 있으며, 보다 폭넓은 해석을 위해서는 정상 청력 집단과 청각 장애 집단을 비교하는 연구가 이어져야 할 것이다. 둘째, 대상자 선 별 조건에 보정 청력을 포함하고자 청력 범위를 통제하였지만 후속 연구에서는 보청기와 인공와우가 가지는 보장구상의 특성이 미칠 수 있는 영향을 비롯하여 청각장애인의 문장이해 수행과 관련 있 는 것으로 알려진 변인들을 탐색할 필요가 있다. 셋째, 본 연구에서 언어 수준의 차이는 어휘력을 기준으로 삼았으나 언어 처리 과정에 서 요구되는 관련 능력은 매우 다양하기 때문에 문장이해와 보다 직접적인 관계가 있을 수 있는 언어 변수를 객관적으로 측정하여 집단을 구분하는 연구가 수행되어야 할 것이다.

그럼에도 불구하고 본 연구는 계속적으로 확대되고 있는 청각장 애 청소년들의 구어를 통한 의사소통 환경을 고려하여 실시되었고 그 결과를 통해 청각장애 청소년의 언어 수준과 의사소통 상대자 가 제공하는 회복전략이 이들이 문장이해 과제를 수행함에 있어 영향을 주는 변인임을 확인하였다는데 그 의의가 있다. 또한 청각 장애 청소년을 어휘력에 기반한 언어 수준에 따라 두 집단으로 구 분한 뒤 문장이해 수행을 비교하였을 때 의사소통 상대자가 제시
하는 회복전략을 활용하여 이해 실패를 극복하는 양상이 두 집단 에서 다르게 나타나며, 특히 언어 수준 하위집단에게는 자극의 어 휘 수를 줄이거나 간결한 문장구조로 제시하는 간략화 전략이 단 순히 선행 자극을 반복하거나 어휘 및 형태를 변형하여 제시하는 전략보다 의사소통 붕괴를 해소하는 데에 상대적으로 유용할 수 있음을 구조화된 측정을 통해 보여주었다. 청각장애 청소년이 겪고 있는 의사소통의 어려움 자체를 고찰하는 연구도 물론 필요하지만 이들이 상호작용하는 의사소통 상대자에 따른 반응 양상을 탐색 하는 노력이 활발히 지속된다면 보다 적극적이고 효율적인 훈련 프 로그램이 만들어지는 바탕이 될 것이며, 원활한 의사소통의 기회 가 실질적으로 확장됨으로써 청각장애 청소년들이 느끼는 의사소 통의 질적 향상에 기여할 수 있을 것으로 기대한다.

\section{REFERENCES}

Berger, K. W. (1973). Consonant confusions in speechreading. Ohio Journal of Speech and Hearing, 8, 10-18.

Choi, I. J. (2001). Responses to requests for clarification in normal and deaf children (Master's thesis). Ewha Womans University, Seoul, Korea.

Coates, J., \& Sutton-Spence, R. (2001). Turn-taking patterns in deaf conversation. Journal of Sociolinguistics, 5, 507-529.

Connor, C. M., Craig, H. K., Raudenbush, S. W., Heavner, K., \& Zwolan, T. A. (2006). The age at which young deaf children receive cochlear implants and their vocabulary and speech-production growth: is there an added value for early implantation? Ear and Hearing, 27, 628-644.

Damen, G. W., van den Oever-Goltstein, M. H., Langereis, M. C., Chute, P. M., \& Mylanus, E. A. (2006). Classroom performance of children with cochlear implants in mainstream education. Annals of Otology, Rhinology \& Laryngology, 115, 542-552.

De Filippo, C. L., \& Scott, B. L. (1978). A method for training and evaluating the reception of ongoing speech. The Journal of the Acoustical Society of America, 63, 1186-1192.

Gagne, J. P., \& Wylliet, K. A. (1989). Relative effectiveness of three repair strategies on the visual-identification of misperceived words. Ear and Hearing, 10, 368-374.

Gallagher, T. M. (1977). Revision behaviors in the speech of normal children developing language. Journal of Speech, Language, and Hearing Research, 20, 303-318.

Heo, H. S., \& Ha, S. H. (2010). The relationship between speech intelligibility and comprehensibility for children with cochlear implants. Phonetics and 
Speech Sciences, 2, 171-178.

Huh, M. J. (1997). Acoustic characteristics of voice of normal and hearing impaired individuals (Master's thesis). Daegu University, Gyeongsan, Korea.

Hwang, H. J. (2013). Working memory abilities and sentence comprehension in normal aging process (Master's thesis). Daegu University, Gyeongsan, Korea. Jeanes, R. C., Nienhuys, T. G., \& Rickards, F. W. (2000). The pragmatic skills of profoundly deaf children. Journal of Deaf Studies and Deaf Education, 5, 237-247.

Jeong, E. H. (2001). A study on the sentence comprehension strategy of students with hearing impairment according to semantical restriction and verbal pattern. Korean Journal of Special Education, 36, 207-232.

Johnson, C., \& Goswami, U. (2010). Phonological awareness, vocabulary, and reading in deaf children with cochlear implants. Journal of Speech, Language, and Hearing Research, 53, 237-261.

Kang, J., \& Ha, S. (2013). The influential factors upon speech intelligibility of adolescents with cochlear implants. Communication Sciences \& Disorders, 18, 318-329.

Kang, W. J. (2011). The effect of interpersonal relations on social development of hearing impaired adolescents. The Journal of Special Children Education, $13,143-161$.

Kim, A. H., \& Hwang, M. (2008). Prediction of reading skill in upper elementary students. Korean Journal of Communication Disorders, 13, 1-25.

Kim, H. S. (1993). A study on the efficient method of teaching vocabulary (Master's thesis). Korea National University of Education, Cheongju, Korea.

Kim, S. H. (2007). A multi-case study on instruction methods to improve vocabulary for students with hearing impairments (Master's thesis). Yongin University, Yongin, Korea.

Kim, T. Y. (2011). Characteristics of communication breakdown of normal children between who have hearing impaired parents and who have parents with no hearing impairment (Master's thesis). Ewha Womans University, Seoul, Korea.

Kim, Y. T., Hong, G. H., Kim, K. H., Jang, H. S., \& Lee, J. Y. (2009). Receptive \& expressive vocabulary test (REVT). Seoul: Seoul Community Rehabilitation Center.

Lee, H. J. (2006). The pragmatic skills of children with hearing impairment: Focused on clarification behavior (Master's thesis). Dankook University, Yongin, Korea.

Lee, J. L. (1993). A quest of teaching method for the hearing-impaired children's elevation of sentence ability (Master's thesis). Daegu University, Gyeongsan, Korea.
Lee, K. S., \& Lee, J. L. (1993). A quest of teaching method for the hearing-impaired children's elevation of sentence ability. Communication Disorder, 16, 37-64.

Lee, Y. M., Sung, J. E., Park, J. M., \& Sim, H. S. (2011). Effects of listener's experience, severity of speaker's articulation and linguistic cues on speech intelligibility in congenitally deafened adults with cochlear implants. Phonetics and Speech Sciences, 3, 125-134.

Lee, Y. S., \& Seok, D. I. (2003). Effectiveness of repair strategies on the sentence comprehension in child with hearing impairment. Korean Journal of Communication Disorders, 8, 271-286.

Lin, H. L., Lawrence, F. R., \& Gorrell, J. (2003). Kindergarten teachers’ views of children's readiness for school. Early Childhood Research Quarterly, 18, 225-237.

Marzolf, C. A., Stewart, M., Nerbonne, M. A., \& Lehman, M. E. (1998). Effects of two repair strategies on speechreading of words and sentences. Journal of the American Academy of Audiology, 9, 243-248.

McAnally, P. L., Rose, S., \& Quigley, S. P. (1999). Reading practices with deaf learners. Austin, TX: Pro-Ed.

McTear, M. F., \& Conti-Ramsden, G. (1992). Pragmatic disability in children. London: Whurr Publishers.

Oh, H. J. (2012). Review of transition education for inclusive education in elementary school for children with hearing impairment. The Korean Society of Education for Hearing-Language Impairments, 3, 21-38.

Ok, J. D., \& Yoon, B. C. (2008). The study of vocabulary understanding ability of hearing impaired middle and high school students. Journal of Speech \& Hearing Disorders, 17, 165-179.

Owens, E., \& Telleen, C. C. (1981). Tracking as an aural rehabilitative process. Journal of the Academy of Rehabilitative Audiology, 14, 259-273.

Park, S. H., \& Bahng, J. H. (2011). The relation among working memory, sentence comprehension and sentence recognition in children with a cochlear implant. Audiology, 7, 40-50.

Paul, P. V., \& Gustafson, G. (1991). Comprehension of high-frequency multimeaning words by students with hearing impairment. Remedial and Special Education, 12, 52-61.

Pisoni, D. B., \& Cleary, M. (2003). Measures of working memory span and verbal rehearsal speed in deaf children after cochlear implantation. Ear and Hearing, 24(1 Suppl), 106S-120S.

Smith, S. L., \& West, R. L. (2006). The application of self-efficacy principles to audiologic rehabilitation: a tutorial. American Journal of Audiology, 15, 46-56. 
Svirsky, M., \& Chin, S. (2000). Speech production. In S. B. Waltzman \& N. L.

Cohen (Eds.), Cochlear implants (pp. 293-309), New York, NY: Thieme Publishing Group.

Tye-Murray, N. (2009). Foundations of aural rehabilitation: children, adults, and their family members (3rd ed.). Clifton Park, NY: Delmar/Cengage Learning.

Tye-Murray, N., \& Kelsey, D. R. (1993). Communication therapy for parents of cochlear implant users. Volta Review, 95, 21-32.

Tye-Murray, N., Purdy, S. C., Woodworth, G. G., \& Tyler, R. S. (1990). Effects of repair strategies on visual identification of sentences. Journal of Speech and Hearing Disorders, 55, 621-627.

Wetherby, A., \& Prizant, B. (2002). Communication and symbolic behavior scales: developmental profile. Baltimore, MD: Paul H. Brookes. 
Appendix 1. 참가자 청력 상세 정보

\begin{tabular}{|c|c|c|c|c|c|}
\hline \multirow{2}{*}{ 참가자 } & \multirow{2}{*}{ 집단 } & \multirow{2}{*}{ 교육 형태 } & 보정 전 청력(dB) & \multirow{2}{*}{$\begin{array}{c}\text { 보정 청력(dB) } \\
\text { 좌/우 }\end{array}$} & \multirow{2}{*}{$\begin{array}{l}\text { 보장구 } \\
\text { 좌/우 }\end{array}$} \\
\hline & & & 좌/우 & & \\
\hline 1 & 상위 & 특수 & $85 / 85$ & $-/ 40$ & $-/ \mathrm{HA}$ \\
\hline 2 & 상위 & 특수 & $120 / 110$ & $25 / 25$ & $\mathrm{Cl} / \mathrm{Cl}$ \\
\hline 3 & 상위 & 특수 & $85 / 90$ & $25 /-$ & $\mathrm{HA} /-$ \\
\hline 4 & 상위 & 특수 & $90 / 100$ & $25 /-$ & $\mathrm{Cl} /-$ \\
\hline 5 & 상위 & 특수 & $90 / 80$ & $45 / 35$ & $\mathrm{HA} / \mathrm{HA}$ \\
\hline 6 & 상위 & 특수 & $90 / 85$ & $45 / 35$ & $\mathrm{HA} / \mathrm{HA}$ \\
\hline 7 & 상위 & 특수 & $110 / 105$ & $-/ 30$ & $-/ \mathrm{Cl}$ \\
\hline 8 & 상위 & 특수 & $110 / 105$ & $35 /-$ & $\mathrm{Cl} /-$ \\
\hline 9 & 상위 & 특수 & $120 / 105$ & $-/ 20$ & $-/ \mathrm{Cl}$ \\
\hline 10 & 상위 & 통합 & $95 / 70$ & $25 / 30$ & $\mathrm{Cl} / \mathrm{HA}$ \\
\hline 11 & 상위 & 통합 & $120 / 115$ & $15 / 25$ & $\mathrm{Cl} / \mathrm{Cl}$ \\
\hline 12 & 상위 & 특수 & $85 / 85$ & $45 / 45$ & $\mathrm{HA} / \mathrm{HA}$ \\
\hline 13 & 상위 & 통합 & $120 / 120$ & $35 / 30$ & $\mathrm{Cl} / \mathrm{Cl}$ \\
\hline 14 & 상위 & 통합 & $90 / 80$ & $45 / 30$ & $\mathrm{HA} / \mathrm{HA}$ \\
\hline 15 & 상위 & 통합 & $95 / 100$ & $35 / 40$ & $\mathrm{HA} / \mathrm{HA}$ \\
\hline 16 & 상위 & 통합 & $100 / 110$ & $25 / 20$ & $\mathrm{Cl} / \mathrm{Cl}$ \\
\hline 17 & 상위 & 특수 & $95 / 110$ & $-/ 30$ & $-/ \mathrm{Cl}$ \\
\hline 18 & 상위 & 통합 & $100 / 115$ & $-/ 30$ & $-/ \mathrm{Cl}$ \\
\hline 19 & 하위 & 특수 & $110 / 120$ & $25 /-$ & $\mathrm{Cl} /-$ \\
\hline 20 & 하위 & 특수 & $120 / 70$ & $25 / 40$ & $\mathrm{Cl} / \mathrm{HA}$ \\
\hline 21 & 하위 & 특수 & $80 / 85$ & $40 / 40$ & $\mathrm{HA} / \mathrm{HA}$ \\
\hline 22 & 하위 & 특수 & $90 / 120$ & $30 /-$ & $\mathrm{Cl} /-$ \\
\hline 23 & 하위 & 특수 & $120 / 80$ & -130 & $-/ \mathrm{Cl}$ \\
\hline 24 & 하위 & 특수 & $75 / 120$ & $20 /-$ & $\mathrm{Cl} /-$ \\
\hline 25 & 하위 & 특수 & 70/70 & $40 /-$ & $\mathrm{HA} /-$ \\
\hline 26 & 하위 & 특수 & $75 / 90$ & $-/ 30$ & $-/ \mathrm{Cl}$ \\
\hline 27 & 하위 & 특수 & $85 / 85$ & $45 / 20$ & $\mathrm{HA} / \mathrm{Cl}$ \\
\hline 28 & 하위 & 특수 & $115 / 75$ & $35 / 40$ & $\mathrm{Cl} / \mathrm{HA}$ \\
\hline 29 & 하위 & 특수 & $85 / 90$ & $40 /-$ & $\mathrm{HA} /-$ \\
\hline 30 & 하위 & 특수 & $90 / 105$ & -130 & $-/ \mathrm{Cl}$ \\
\hline 31 & 하위 & 통합 & $120 / 120$ & -130 & $-/ \mathrm{Cl}$ \\
\hline 32 & 하위 & 통합 & $90 / 105$ & $-/ 25$ & $-/ \mathrm{Cl}$ \\
\hline 33 & 하위 & 특수 & $115 / 120$ & -130 & $-/ \mathrm{Cl}$ \\
\hline 34 & 하위 & 특수 & $120 / 105$ & $20 / 20$ & $\mathrm{Cl} / \mathrm{Cl}$ \\
\hline 35 & 하위 & 특수 & $115 / 120$ & $-/ 30$ & $-/ \mathrm{Cl}$ \\
\hline 36 & 하위 & 통합 & $115 / 120$ & $30 / 35$ & $\mathrm{Cl} / \mathrm{Cl}$ \\
\hline
\end{tabular}


Appendix 2. 문장-그림 일치 과제 예시

검사문장: 아빠가 모자 쓴 남자를 여자에게 데려간다.

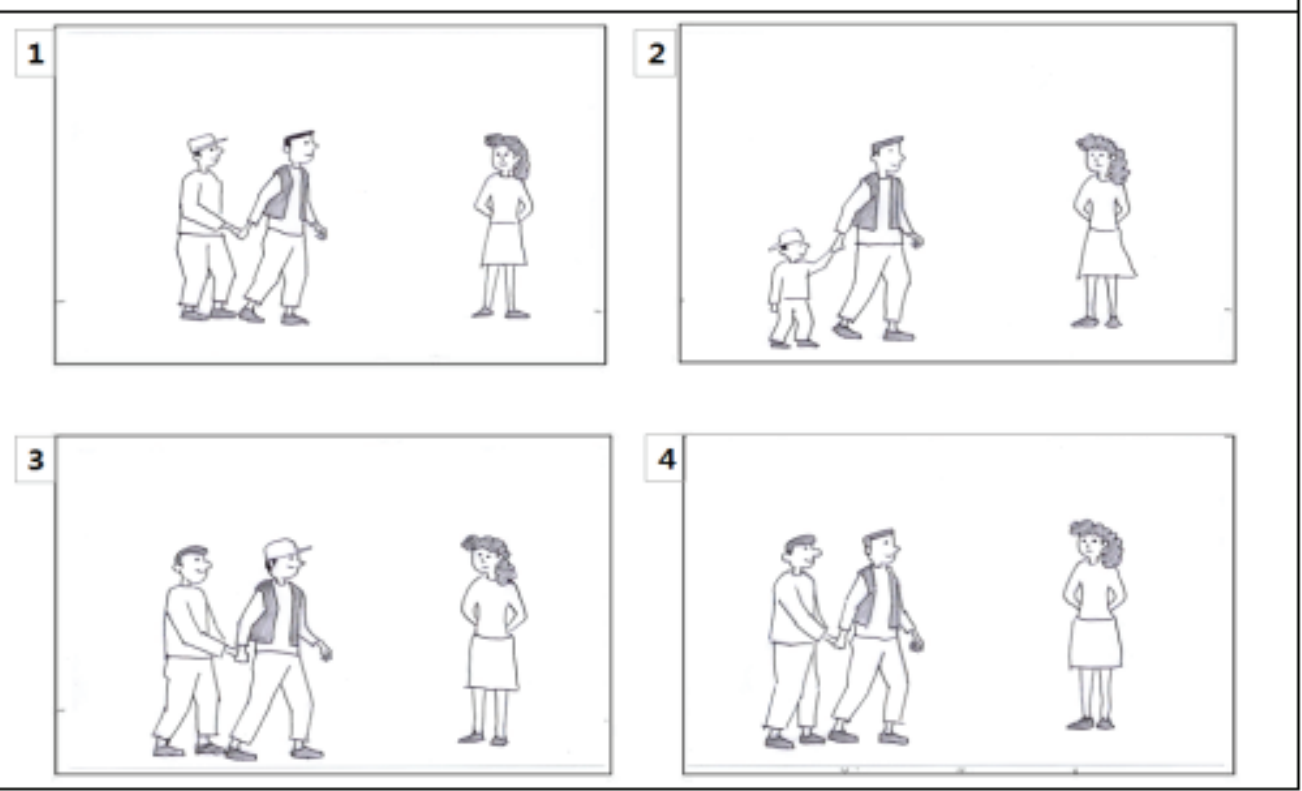


Appendix 3. 검사문장 및 의사소통 회복전략 적용 문장 목록

\begin{tabular}{|c|c|c|c|}
\hline & 1차 제시 문장 & 의사소통 회복전략을 적용한 문장 & 전략 유형 \\
\hline 1 & 간호사가 환자복을 입히고 있다. & 간호사가 환자복을 입히고 있다. & 반복(Repetition) \\
\hline 2 & 아버지가 식사를 마치고 책을 보고 있다. & 아버지가 식사를 마치고 책을 보고 있다. & \\
\hline 3 & 엄마가 풍선을 들고 있는 아이의 사진을 찍고 있다. & 엄마가 풍선을 들고 있는 아이의 사진을 찍고 있다. & \\
\hline 4 & 할아버지는 과일을 드시지도 밥을 드시지도 않았다. & 할아버지는 과일을 드시지도 밥을 드시지도 않았다. & \\
\hline 5 & 고양이가 높은 의자 뒤에 있다. & 고양이가 높은 의자 뒤에 있다. & \\
\hline 6 & 수영복이 없어서 물속에 들어가지도 놀지도 못했다. & 수영복이 없어서 물속에 들어가지도 놀지도 못했다. & \\
\hline 7 & 엄마가 아기에게 고양이를 보여준다 & 엄마가 아기에게 고양이를 보여준다. & \\
\hline 8 & 빗자루를 든 남자가 구석에 비스듬히 기대어 서 있다. & 빗자루를 든 남자가 구석에 비스듬히 기대어 서 있다. & \\
\hline 9 & 할머니는 할아버지에게 장바구니를 들게 했다. & 할머니는 할아버지에게 장바구니를 들게 했다. & \\
\hline 10 & 여자가 양복 입은 남자를 끌어준다. & 여자가 양복 입은 남자를 끌어준다. & \\
\hline 1 & 남자가 여자한테 잡혔다. & 여자가 남자를 잡았다. & 바꾸어 말하기(Revision) \\
\hline 2 & 할머니가 수건을 개고 할아버지도 똑같이 했다. & 할머니와 할아버지가 같이 수건을 개고 있다. & \\
\hline 3 & 뱀이 너구리를 잡아먹으려 한다. & 뱀이 너구리를 잡아먹기 직전이다. & \\
\hline 4 & 여자가 아이를 안은 남자를 따라간다. & 아이를 안은 남자를 여자가 따라간다. & \\
\hline 5 & 방금 전에 함박눈이 왔었다. & 좀 전까지 함박눈이 왔었다. & \\
\hline 6 & 야구선수가 야구공을 던지려고 한다. & 남자가 공을 던지기 직전이다. & \\
\hline 7 & 사자가 곰한테 쫓기고 있다. & 곰이 사자를 쫓아가고 있다. & \\
\hline 8 & 아빠가 모자 쓴 남자를 여자에게 데려간다. & 아빠와 모자 쓴 남자가 여자에게 간다 & \\
\hline 9 & 집 안의 불빛이 매우 밝다. & 집 안의 불이 매우 환하다. & \\
\hline 10 & 남자가 자전거를 타는 여자에게 손을 흔들었다. & 자전거를 타는 여자에게 남자가 손을 흔들었다. & \\
\hline 1 & 두 사람 빼고는 모두 반밖에 안 먹었다. & 두 사람만 다 먹었다. & 간략화(Simplification) \\
\hline 2 & 아이가 울면서 뛰어와 엄마에게 안기려고 한다 & 아이가 울면서 엄마한테 뛰어온다. & \\
\hline 3 & 할아버지가 가진 다섯 개의 지팡이 중에서 서너 개는 모양이 비슷하다. & 할아버지 지팡이 중 서너 개는 모양이 비슷하다. & \\
\hline 4 & 남자는 안경을 쓴 여자와 함께 걷고 있다. & 남자가 안경 쓴 여자와 걷는다. & \\
\hline 5 & 할머니는 시장에서 생선을 팔다가 다 팔고 나서야 집으로 돌아갔다. & 할머니는 생선을 다 팔고 집에 갔다. & \\
\hline 6 & 남자가 자신의 얼굴을 닦는다. & 남자가 세수를 한다. & \\
\hline 7 & 할머니는 목에 수건을 두르고 있다. & 목에 수건을 걸치고 있다. & \\
\hline 8 & 할머니가 아빠에게 아기를 안겨 주었다. & 아빠가 아기를 안았다. & \\
\hline 9 & 제사상을 차리는 것은 누워서 떡 먹기이다. & 제사상을 차리는 것은 정말 쉽다. & \\
\hline 10 & 강아지가 풀밭에 누워서 잠을 자고 있다. & 강아지가 풀밭에서 잔다. & \\
\hline
\end{tabular}




\section{국문초록}

\section{청각장애 청소년의 언어능력과 의사소통 회복 전략에 따른 문장 이해 특성 이지아 $\cdot$ 최소영 2 \\ '단국대학교 특수교육대학원 특수교육학과, ${ }^{2}$ 단국대학교 특수교육대학원}

배경 및 목적: 본 연구는 청각장애 청소년의 언어능력과 의사소통에 참여하는 상대자가 제공하는 회복전략 유형에 따른 문장이해 수 행의 차이를 살펴보고자 하였다. 방법: 본 연구의 참가자는 1)보장구를 착용하고 있으며, 2)보정청력은 경도난청 범위(20-45 dB)에 속하 고, 3)구어를 제1언어로 사용하는 청각장애 청소년이었다. 생활연령 14-18세, 언어연령 8-14세 범위에 속하는 36명을 선별하였고, 어휘 력에 근거한 언어 수준을 기준으로 상위집단(18명)과 하위집단(18명)을 구분하였다. 문장-그림 일치 과제를 사용하여 구조화된 의사소 통 상황을 설정하였으며, 문장이해에 실패한 경우를 의사소통 단절로 간주하여 의사소통 상대자로서 연구자가 세 가지 유형의 회복전 략(반복, 바꾸어 말하기, 간략화)을 제시하였다. 결과: 언어 수준 상위집단이 하위집단에 비해 문장이해 반응 정확도가 높았고, 의사소 통 상대자가 회복전략을 제공한 이후 두 집단 모두 반응 정확도가 향상되었다. 회복전략 유형별 문장이해 반응 정확도에서 전략 간에 유의한 차이가 나타나지 않은 상위집단과 달리, 하위집단은 간략화 전략을 사용했을 때 반복이나 바꾸어 말하기 전략보다 높은 반응 정확도를 보였다. 논의 및 결론: 본 연구 결과는 의사소통 상대자의 회복전략 사용이 의사소통 단절을 회복하는 데 도움이 되며, 대상 자의 언어 수준에 따라 효율적으로 활용하는 회복전략에 차이가 있을 수 있음을 시사하였다. 이를 바탕으로 청각장애 청소년의 언어능 력과 그들의 의사소통 파트너를 함께 고려하는 노력이 필요함을 제안하였다.

핵심어: 청각장애 청소년, 의사소통 회복전략, 언어능력

이 논문은 제 1 저자의 석사학위 논문을 요약한 것임.

\section{참고문헌}

강우진(2011). 청각장애청소년이 갖는 대인관계성향이 사회성 발달에 미치는 영향. 특수아동교육연구, 13, 143-161.

강지송, 하승희(2013). 인공와우를 이식한 청소년의 말명료도에 영향을 미치는 요인. 언어청각장애연구, 18, 318-329.

김성현(2007). 청각장애학생의 어휘력 향상을 위한 교수-학습방법 다중사례연구. 용인대학교 대학원 석사학위논문.

김애화, 황민아(2008). 초등학교 고학년의 읽기능력에 영향을 미치는 읽기관련변인에 관한 연구. 언어청각장애연구, 13, 1-25.

김영태, 홍경훈, 김경희, 장혜성, 이주연(2009). 수용·표현어휘력검사(REVT). 서울: 서울장애인종합복지관.

김태연(2011). 수화를 사용하는 청각장애 가정 건청 아동의 의사소통단절 및 발화수정전략 특성. 이화여자대학교 대학원 석사학위논문.

김현숙(1993). 효율적인 어휘 지도 방안 연구. 한국교원대학교 대학원 석사학위논문.

박소현, 방정화(2011). 인공와우 착용 아동의 작업기억, 문장이해력과 문장인지도 간의 관계. 청능재활, 7, 40-50.

오혜정(2012). 청각장애유아의 초등학교 통합교육 준비를 위한 전환교육. 한국청각.언어장애교육연구, 3, 21-38.

옥정달, 윤병천(2008). 청각장애학생의 어휘력에 관한 연구. 언어치료연구, 17, 165-179.

이규식, 이정열(1993). 청각장애아동의 문장력 향상을 위한 교수법의 탐색. 난청과 언어장애, 16, 37-64.

이영미, 성지은, 박정미, 심현섭(2011). 청자의 경험, 화자의 조음 중증도, 단서 유형이 인공와우이식 선천성 농 성인의 말명료도에 미치는 영향. 말소리

와음성과학, 3, 125-134.

이영숙, 석동일(2003). 의사소통 회복전략이 고도난청 아동의 문장이해력에 미치는 효과. 언어청각장애연구, 8, 271-286.

이정열(1993). 청각장애아의 문장력 향상을 위한 교수법의 탐색. 대구대학교 대학원 석사학위논문.

이혜진(2006). 청각장애 아동의 화용기술 분석: 명료화 행위를 중심으로. 단국대학교 대학원 석사학위논문.

정은희(2001). 청각장애 학생의 문장 이해에 관한 연구-의미적 제약성과 서술어 유형에 따른 이해 전략을 중심으로. 특수교육학연구, 36, 207-232. 
최인자(2001). 청각장애 아동의 명료화 요구에 대한 발화수정전략의 사용 연구. 이화여자대학교 대학원 석사학위논문.

허명진(1997). 정상인과 청각장애인 음성의 음향학적 특성. 대구대학교 대학원 석사학위논문.

허현숙, 하승희(2010). 조음중증도에 따른 인공와우이식 아동들의 말명료도와 이해가능도의 상관연구. 말소리와 음성과학, 2, 171-178.

황혜진(2013). 정상 노화과정에서의 작업기억 능력과 문장이해력. 대구대학교 대학원 석사학위논문. 